\title{
Evaluation of tooth staining with red wine after tooth bleaching with nonthermal atmospheric pressure plasma.
}

\author{
Gyoo Cheon Kim', Man Seok Han², Seoul Hee $\mathrm{Nam}^{3 *}$ \\ ${ }^{1}$ Department of Oral Anatomy, School of Dentistry, Pusan National University, Yangsan-si, 50612, Republic of Korea \\ ${ }^{2}$ Department of Radiological Science, Kangwon National University, Samcheok-si, 25949, Republic of Korea \\ ${ }^{3}$ Department of Dental Hygiene, Kangwon National University, Samcheok-si, 25949, Republic of Korea
}

\begin{abstract}
We conducted to investigate the tooth color change caused by $15 \%$ carbamide peroxide (CP) used as a self-bleaching agent containing 5.4\% low-concentration $\mathrm{H}_{2} \mathrm{O}_{2}$ with nonthermal atmospheric pressure plasma, and the effect of such tooth bleaching method on staining sensitivity to red wine. Ten extracted intact human teeth without signs of fracture, dental caries, or structural anomalies were used in this experiment. One half of each tooth was randomly assigned to either the control or the experimental group. Group 1 (control group) was treated with a uniform $1 \mathrm{~mm}$ layer of $15 \% \mathrm{CP}$ gel application which contained 5.4\% $\mathrm{H}_{2} \mathrm{O}_{2}$ (every $10 \mathrm{~min}$, Kool White 15\%, Pac-Dent International, Walnut, CA, USA) alone. Group 2 (experimental group) received a $15 \% \mathrm{CP}$ and plasma for $30 \mathrm{~min}$. The tip of the static plasma device was positioned at a $1 \mathrm{~cm}$ distance from the tooth surface. And then, the teeth were immersed in red wine (Palacio De Anglona Tinto Semidulce-red wine subgroup) for seven days. The buccal surface of each tooth was based on the Commission Internationale de L'Eclairage (CIE) Lab Color System which is widely used for tooth color evaluation. The control and experimental groups showed significant differences in brightness after $30 \mathrm{~min}$. After 7 day immersion in red wine, the mean $\Delta E$ values for the plasma and $15 \%$ CP combinational treatment were approximately 1.56-fold smaller than those for the treatment without plasma $(\mathbf{P}<\mathbf{0 . 0 5})$. The combinational treatment with nonthermal atmospheric pressure plasma and $15 \%$ carbamide peroxide $(\mathrm{CP})$ has an excellent tooth bleaching effect and can maintain the bleached tooth's color stability due to its low staining sensitivity to pigmentation after bleaching.
\end{abstract}

Keywords: Discoloration, Color change, Nonthermal atmospheric pressure plasma, Tooth bleaching, Staining, Red wine.

Accepted on November 01, 2017

\section{Introduction}

With the recent rise in dental-care patients' aesthetic demands owing to modern people's desire to improve the quality of their lives, tooth bleaching-expressing one's good health and enhancing one's beauty by making one's teeth whiter-has been receiving increasing attention of late [1]. Tooth bleaching is an aesthetic procedure for removing the elements that stain the teeth, making the teeth brighter and improving their color [2]. Thus, it is popular as a conservative method of making the teeth whiter or recovering the aesthetics of discolored teeth [3]. Tooth bleaching can be categorized by method employed, performing practitioner, and material used. It can be broadly classified into professional bleaching and self-bleaching, and between these, professional bleaching using 30-35\% highconcentration hydrogen peroxide $\left(\mathrm{H}_{2} \mathrm{O}_{2}\right)$ is preferred because of its ability to achieve a rapid bleaching effect in a short time [4]. The mechanism of the tooth bleaching is not yet clear, but it is known that bleaching is achieved by oxidation reaction [5]. During the reaction, $\mathrm{H}_{2} \mathrm{O}_{2}$ oxidizes the structural formula of the colorant in the interprismatic space of the enamel, thereby causing a bleaching effect. As the bleaching agent decomposes, the complex structural formula of the colorant on the tooth surface is simplified, the reflectance of light changes accordingly, and consequently, the tooth looks brighter [6].

A tooth can be more deeply penetrated with the use of a light source [7], but besides the fact that the light source's actual role has yet to be firmly established, light sources can cause thermal damage in the pulp tissue [8]. As such, a new bleaching method that is effective at low $\mathrm{H}_{2} \mathrm{O}_{2}$ concentrations but does not cause thermal damage is being sought. Nonthermal atmospheric pressure plasma sources have been used for biomedical applications since 2000 [9-11] because plasma, the fourth state of matter (after the solid, liquid, and gas states) contains many radicals, a strong electric field, and 
charged particles. Since recently, studies on a new tooth bleaching method involving the use of nonthermal atmospheric pressure plasma have been actively conducted, and these studies have reported the superior effect of this new tooth bleaching method compared to the conventional method [9,12-15]. This is because plasma produces a larger amount of hydroxyl radical $(\cdot \mathrm{OH})$, which plays an important role in tooth bleaching as it increases the bleaching efficacy $[9,12,13]$.

The previous studies on the efficacy and principles of bleaching have reported side effects like hyperesophoria after bleaching, gingival-and soft-tissue burns, and changes in taste [16]. Moreover, Hersek et al. [17] observed that tea, coffee, and wine cause severe staining on the tooth enamel. It has also been reported that the effect of bleaching is not permanent, and that even after bleaching, tooth discoloration may be caused by extraneous factors like the consumption of coffee, green tea, black tea, cola, and red wine [18]. As tooth bleaching causes a change in the tooth's surface characteristics, the bleached tooth may become more sensitive than before to staining. There have been almost no studies, however, that applied the aforementioned new tooth bleaching method involving the use of nonthermal atmospheric pressure plasma and that investigated its effect on the bleached tooth's color stability against beverages causing tooth surface staining. As such, this study aimed to investigate the tooth color change caused by $15 \%$ carbamide peroxide (CP) used as a self-bleaching agent containing 5.4\% low-concentration $\mathrm{H}_{2} \mathrm{O}_{2}$ with nonthermal atmospheric pressure plasma, and the effect of such tooth bleaching method on staining sensitivity to red wine.

\section{Materials and Methods}

\section{Plasma device}

For this experiment, the plasma source is composed of an alumina tube with an internal diameter of $4 \mathrm{~mm}$, inner stainless still electrode and outer copper electrode. Argon was used as a carrier gas at 2 (standard liters per minute (slm). Outer electrode is grounded and an AC high voltage generated by high voltage circuit which can increase the voltage up to $10 \mathrm{kV}$ with frequency of $15 \mathrm{kHz}$. When applied voltage is over 2.8 $\mathrm{kHz}$, the Argon plasma is generated in an alumina tube (Figure $1)$.

\section{Tooth preparation}

Ten extracted intact human teeth without signs of fracture, dental caries, or structural anomalies were used in this experiment. All teeth were removed with a soft-tissue ultrasonic scaler and polished in a dental rubber cup with water or pumice slurry prophylaxis. The roots were cut with watercooling using a diamond saw (Struers Minitom, Copenhagen, Denmark) at the cement-enamel junction. The crown was cut in half longitudinally and cut surfaces were coated with two layers of nail varnish.

\section{Tooth bleaching procedure and re-stain process}

Before the tooth bleaching, the buccal surface of each tooth was photographed using a digital-imaging system provided by a stereomicroscope (SZCTV, Olympus, Tokyo, Japan) at 10X magnification. One half of each tooth was randomly assigned to either the control or the experimental group $(n=10)$. Group 1 (control group) was treated with a uniform $1 \mathrm{~mm}$ layer of $15 \%$ $\mathrm{CP}$ gel application which contained $5.4 \% \mathrm{H}_{2} \mathrm{O}_{2}$ (every $10 \mathrm{~min}$, Kool White 15\%, Pac-Dent International, Walnut, CA, USA) alone. Group 2 (experimental group) received a $15 \% \mathrm{CP}$ and plasma for $30 \mathrm{~min}$. The tip of the static plasma device was positioned at a $1 \mathrm{~cm}$ distance from the tooth surface. After 30 min application, the teeth were thoroughly rinsed to remove all the gel with distilled water and dried with sterile gauze. And then, the sectioned teeth were immersed in red wine (Palacio De Anglona Tinto Semidulce-red wine subgroup) for seven days.

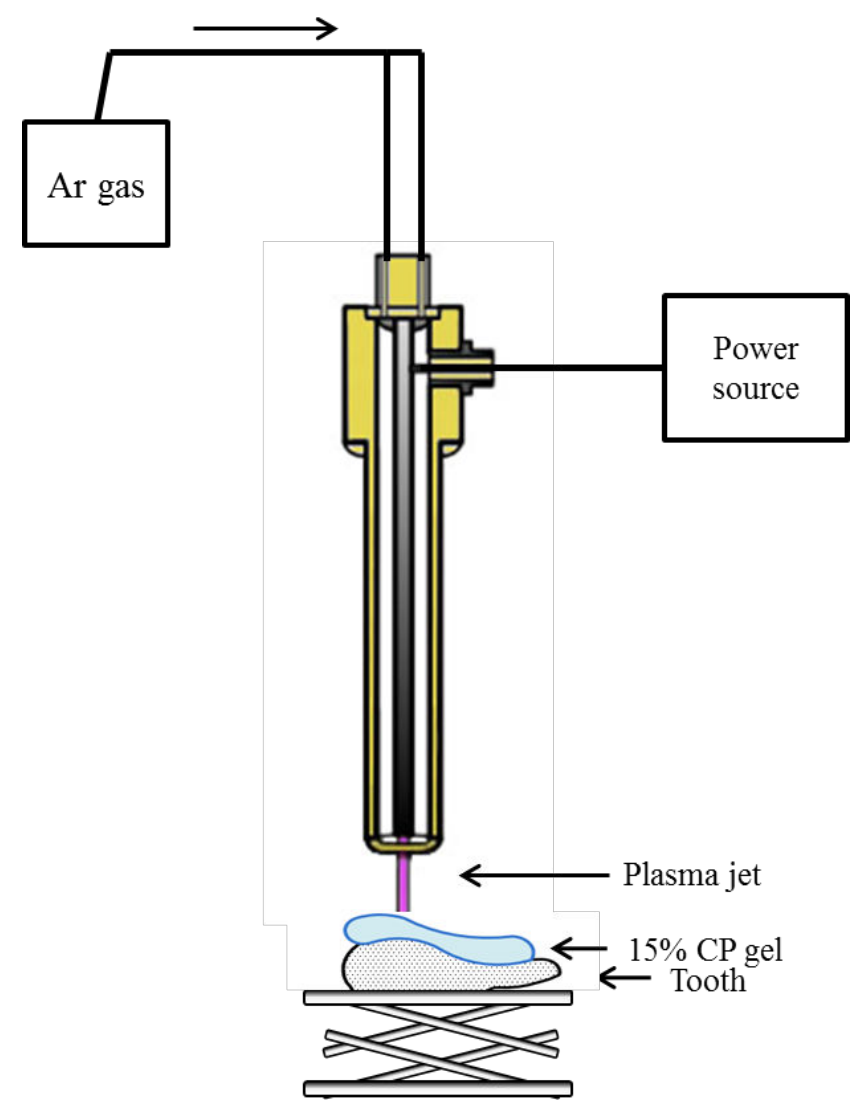

Figure 1. The tooth bleaching process using non-thermal atmospheric pressure plasma.

\section{Measurement of color change}

The color change of each tooth was based on the Commission Internationale de L'Eclairage (CIE) Lab Color System which is widely used for tooth color evaluation $[19,20]$. The differences in the values of $\mathrm{L}^{*}, \mathrm{a}^{*}$, and $\mathrm{b}^{*}$ in each group were measured using Adobe Photoshop CS2 (Adobe Systems, San Jose, CA, USA). The overall color changes $(\Delta E)$ were assessed were calculated according to the following formula: 
$\Delta E \sqrt{\left(\Delta L^{*}\right)^{2}+\left(\Delta a^{*}\right)^{2}+\left(\Delta b^{*}\right)^{2}}$

\section{Statistical analysis}

The difference in color changes between the control and experimental groups was tested with a 95\% significance level, using SPSS (Version 18, SPSS, Chicago, IL, USA). Student's t-test was used to determine the difference in $\Delta$ values between tooth bleaching without plasma and with plasma.

\section{Results}

\section{Color change in red wine after tooth bleaching}

The control and experimental groups showed significant differences in brightness after $30 \mathrm{~min}$ (Figure 2). Table 1 showed the average $\Delta E \pm$ standard deviation (SD). The mean $\Delta E$ values of Group 2 were approximately 1.83 -fold larger than those of Group $1(\mathrm{P}<0.05)$, but after $7^{\text {th }}$ day immersion in red wine, the mean $\Delta E$ values for the plasma and lowconcentration $15 \% \quad \mathrm{CP}$ combinational treatment were approximately 1.56 -fold smaller than those for the treatment without plasma $(\mathrm{P}<0.05)$ (Figure 3$)$.

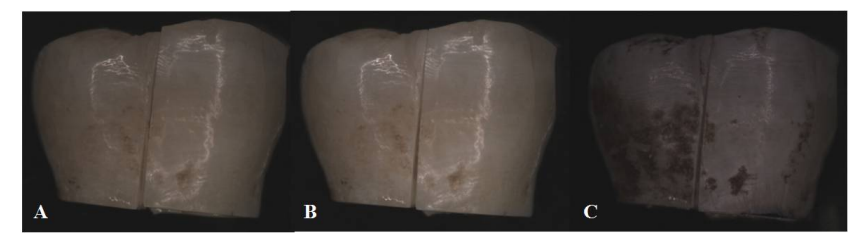

Figure 2. The tooth bleaching effect of plasma and $15 \%$ CP. (A) Photograph of the tooth before treatment; (B) after $30 \mathrm{~min}(C)$ after $7^{\text {th }}$ day of immersion in red wine.

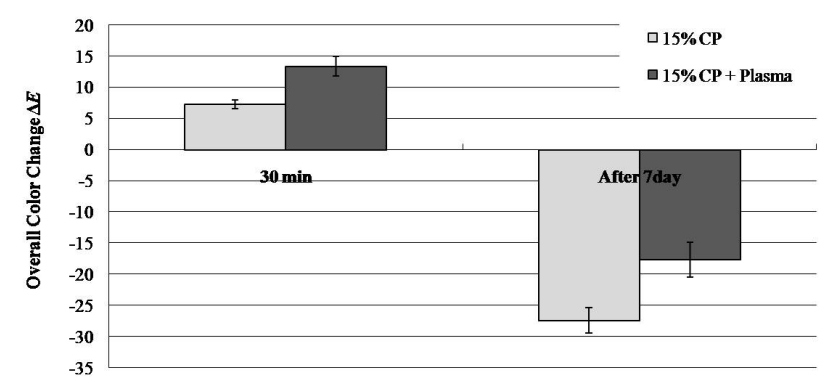

Figure 3. The alteration of overall color changes ( $\Delta E)$ after tooth bleaching and the immersion in red wine up to $7^{\text {th }}$ day.

\section{Discussion}

Bright teeth are more attractive than dull teeth and can improve one's self-esteem. As such, in dental care, not only the demand for better dental health but also that for a better aesthetic appearance is increasing [20]. In terms of the latter, the color of the teeth greatly influences the appearance. As such, an increasing number of people today are seeking to make their teeth whiter to show better dental health and to enhance their beauty, and consequently, more and more dental clinics are performing tooth bleaching [21]. Tooth bleaching effectively improves the color of the teeth and is performed in various ways in clinical practice, but professional bleaching is preferred due to its ability to achieve a rapid bleaching effect in a short time [4]. The use of high-concentration $\mathrm{H}_{2} \mathrm{O}_{2}$ as a professional bleaching agent, however, has been reported to increase the staining after bleaching [22,23]. This side effect has been attributed to the staining materials' penetration of the tooth enamel surface that has been damaged by bleaching with high-concentration $\mathrm{H}_{2} \mathrm{O}_{2}$, thereby resulting in a faster exogenous pigmentation than before bleaching [24]. There is an ongoing controversy with regard to the impact of tooth bleaching using high-concentration $\mathrm{H}_{2} \mathrm{O}_{2}$ on the tooth enamel surface $[25,26]$.

Color stability is one of the most important requirements for maintaining long-term dental aesthetics, and color change, pigmentation, etc. cause dental aesthetic discordance [27]. Pak [28] reported that coffee, red wine, and tea cause tooth staining to a great extent, and it has been reported elsewhere that beverages and foods like red wine, cola, soy sauce, red pepper paste, coffee, and oolong tea are major causes of staining of the natural teeth, resin, and artificial teeth [29]. Therefore, to maintain the bleached tooth surface's color stability from pigmentation, it is necessary to confirm the bleached tooth surface's sensitivity to staining. It was revealed that plasma treatment could improve the efficacy of tooth bleaching by removing the proteins on the tooth surface [9]. Nam et al. [30] reported that the combined use of plasma and $15 \% \mathrm{CP}$ for tooth bleaching provides color stability over a 6-month period. The analysis of its impact on the tooth surface showed that tooth bleaching using plasma with $15 \% \mathrm{CP}$ did not influence the microhardness and the mineral content of dental hard tissues [31]. Studies on tooth bleaching using plasma are steadily being conducted, and not only such tooth bleaching method's tooth bleaching effect but also the resulting stability of the tooth surface has been proven.

Table 1. The $\Delta E \pm S . D$ and P-values obtained by tooth bleaching with/ without plasma.

\begin{tabular}{|c|c|c|c|c|c|}
\hline \multirow[t]{2}{*}{ Observation times } & \multirow{2}{*}{$\begin{array}{l}\text { Bleachi } \\
\text { ng } \\
\text { agents }\end{array}$} & \multirow[t]{2}{*}{$\mathbf{N}$} & \multicolumn{2}{|c|}{ Mean $\Delta E \pm \mathrm{SD}$} & \multirow{2}{*}{$\begin{array}{l}\text { t-test } \\
\text { P-values }\end{array}$} \\
\hline & & & $\begin{array}{l}\text { Without } \\
\text { plasma }\end{array}$ & Plasma & \\
\hline $\begin{array}{l}\text { Immediately after } \\
30 \text { min bleaching }\end{array}$ & $15 \% \mathrm{CP}$ & $\begin{array}{l}1 \\
0\end{array}$ & $7.31 \pm 0.70$ & $13.34 \pm 1.55$ & $0.037^{*}$ \\
\hline $\begin{array}{lllr}\text { After } 7 & \text { day } & \text { of } \\
\text { immersion } & \text { in } & \text { red } \\
\text { wine } & & \end{array}$ & $15 \% \mathrm{CP}$ & $\begin{array}{l}1 \\
0\end{array}$ & $-27.41 \pm 2.04$ & $\begin{array}{l}-17.62 \quad \pm \\
2.80\end{array}$ & $0.043^{*}$ \\
\hline
\end{tabular}

*The significant differences between the two groups by Student t-test $(P<0.05)$.

There has been no report, however, on the impact of tooth bleaching using plasma on the bleached tooth surface's staining. As such, this study was conducted to confirm the tooth color change after bleaching with plasma and lowconcentration $\mathrm{CP}$, and such method's impact on tooth surface staining by red wine. As a result, it was confirmed that the plasma and $15 \% \mathrm{CP}$ combinational treatment causes less 
staining on the bleached tooth surface than the treatment without plasma. After $7^{\text {th }}$ day immersion in red wine of a tooth that had been bleached using the plasma and $15 \% \mathrm{CP}$ combinational treatment, 1.56-fold lower tooth surface staining was shown compared to the tooth that had been bleached without using plasma $(\mathrm{P}<0.05)$. This demonstrated that tooth bleaching using plasma more effectively brightens the tooth surface and causes less tooth surface staining. These results suggest that the use of plasma for tooth bleaching whitens only the organic matters in the tooth and does not damage the inorganic matters or cause any other harmful effect on the tooth surface, thereby resulting in less staining of the bleached tooth by red wine. Based on these results, it was confirmed that the plasma and $15 \% \mathrm{CP}$ combinational treatment has low sensitivity to bleached-tooth staining. Therefore, the plasma and $15 \% \mathrm{CP}$ combinational treatment for tooth bleaching was verified in this study to have an excellent tooth bleaching effect and to be a safe method that does not cause tooth surface staining.

\section{Conclusion}

The combinational treatment with nonthermal atmospheric pressure plasma and $15 \% \mathrm{CP}$ has an excellent tooth bleaching effect and can maintain the bleached tooth's color stability due to its low staining sensitivity to pigmentation after bleaching.

\section{Acknowledgement}

This research was supported by Basic Science Research Program through the National Research Foundation of Korea (NRF) funded by the Ministry of Science, ICT and Future Planning (2017R1C1B5074410). This study was supported by 2017 Research Grant from Kangwon National University (No. 620170149).

\section{References}

1. Donovan TE, Derbabian K, Kaneko L, Wright R. Esthetic considerations in removable prosthodontics. J Esthet Restor Dent 2001; 13: 241-253.

2. Heymann H. Tooth whitening facts and fallacies. Br Dent $\mathrm{H}$ 198: 514, 2005.

3. Brunton PA, Aminian A, Pretty IA. Vital tooth bleaching in dental practice: 2. novel bleaching systems. Dent Update 2006; 33: 357-362.

4. Leonard R. Efficacy, longevity, side effects of and patient perceptions of nightgaurd vital bleaching. Compend Contin Educ Dent 1998; 19: 766-744.

5. Joiner A. The bleaching of teeth: a review of the literature. J Dent 2006; 34: 412-419.

6. Shim SY, Jung SH. Effect of fluoridated bleaching agents and post-treatment fluoride application on the color and microhardness of enamel surface. J Dent Hyg Sci 2010; 10: 298-300.

7. Buchalla W, Attin T. External bleaching therapy with activation by heat, light or laser-a systematic review. Dent Mater 2007; 23: 586-596.
8. Trindade FZ, Ribeiro AP, Sacono NT, Oliveira CF, Lessa FC, Hebling J , Costa CA. Trans-enamel and trans-dentinal cytotoxic effects of a $35 \% \mathrm{H} 2 \mathrm{O} 2$ bleaching agent on an odontoblast cell line after consecutive applications. Int Endod J 2009; 42: 516-524.

9. Lee HW, Kim GJ, Kim JM, Park JK, Lee JK, Kim GC. Tooth bleaching with nonthermal atmospheric pressure plasma. J Endod 2009; 35: 587-591, 2009.

10. Lloyd G, Friedman G, Jafri S, Schultz G, Fridman A, Harding K: Gas plasma: medical uses and developments in wound care. Plasma Process Polym 2010; 7: 194-211.

11. Kang SK, Choi MY, Koo IG. Reactive hydroxyl radicaldriven oral bacterial inactivation by radio frequency atmospheric plasma. Appl Phys Lett 2011; 98: 143702-143705.

12. Park JK, Nam SH, Kwon HC, Mohamed AAH, Lee JK, Kim GC. Feasibility of nonthermal atmospheric pressure plasma for intracoronal bleaching. Int Endod J 2011; 44: 170-175.

13. Nam SH, Lee HW, Cho SH, Lee JK, Jeon YJ, Kim GC. High-efficiency tooth bleaching using non-thermal atmospheric pressure plasma with low concentration of hydrogen peroxide. J Appl Oral Sci 2013; 21: 265-270.

14. Kim GC, Lee HW, Byun JH, Chung J, Jeon YC, Lee JK. Dental applications of low-temperature nonthermal plasmas. Plasma Process Polym 2013; 10: 199-206.

15. Nam SH, Lee HJ, Hong JW, Kim GC. Efficacy of nonthermal atmospheric pressure plasma for tooth bleaching. Sci World J 2015; 2015: 1-5.

16. Marson FC, Sensi LG, Vieira LC, Araujo E. Clinical evaluation of in-office dental bleaching treatments with and without the use of light-activation sources. Oper Dent 2008; 33: $15-22$.

17. Hersek N, Canay S, Uzun G, Yildiz F. Color stability of denture base acrylic resins in three food colorants. J Prosthet Dent 1999; 81: 375-379.

18. Choi EJ, Moon SH, Mun SR. Color change of food staining and bleaching on composite resin. J Dent Hyg Sci 2012; 12: 477-485.

19. Villalta P, Lu H, Okte Z, Garcia-Godoy F, Powers JM. Effects of staining and bleaching on color change of dental composite resins. J Prosthet Dent 2006; 95: 137-142.

20. Grosofsky A, Adkins BR, Meyer L, Krueger L, Meyer J, Torma P. Tooth color effects on judgements of attractiveness and age. Percept Mot Skills 2003; 96: 43-48.

21. Haywood VB, Heumann HO. Nightguard vital bleaching. Queentessence Int 1989; 20: 173-176.

22. Hegedus C, Bistey T, Flora-Nagy E, Keszthelyi G, Jenei A. An atomic force microscopy study on the effect of bleaching agents on enamel surface. J Dent 1999; 27: 509-515.

23. Tredwin CH, Naik S, Lewis NJ, Scully C. Hydrogen peroxide tooth-whitening (bleaching) products: review of advense effects and safety issues. Br Dent J 2006; 200: 371-376. 
24. Cavalli V, Arrais CAG, Giannin M, Ambrosano GMB. High-concentrated carbamide peroxide bleaching agents effects on enamel surface. J Oral Rehabil 2004; 31: 155-159.

25. Sagel PA, Jeffers ME, Gibb RD, Gerlach RW. Overview of a professional tooth-whitening system containing $6.5 \%$ hydro-gen Peroxide whitening strips. Compend Contin Educ Dent 2002; 23: 9-15.

26. Caneppele TM, Torres CR. Influence of surfactants on the effectiveness of bleaching gels. Clin Oral Investing 2009; 21: 407-414.

27. Jeong YJ, Lim JH, Cho IH, Lim HS. Color stability of ceromers in three food colorants. J Korean Acad Prosthodont 2003; 41: 136-147.

28. Park JW. Understanding of the color in composite resin. J Kor Acad Cons Dent 2011; 36: 271-279.

29. Omata Y, Uno S, Nakaoki Y. Staining of hybrid composites with coffee, oolong tea, or red wine. Dent Mater J 2006; 25: 125-131.
30. Nam SH, Lee HW, Hong JW, Lee HJ, Kim GC. Enhanced long-term color stability of teeth treated with hydrogen peroxide and non-thermal atmospheric pressure plasma jets. Plasma Process Polym 2014; 11: 1010-1017.

31. Nam SH, Hong JW, Lee HJ, Jeon YC, Kim GC. Safety of nonthermal atmospheric pressure plasma for tooth bleaching evaluated in terms of microhardness and mineral content. J Phys D: Appl Phys 2017; 50: 345402-34505.

\section{*Correspondence to}

Seoul Hee Nam

Department of Dental Hygiene

College of Health Science

Kangwon National University

Republic of Korea 